\title{
Bargaining merger terms and the effect on the announcement returns ${ }^{\text {果 }}$
}

\author{
Paulo J. Pereira ${ }^{\mathrm{t}}$ and Artur Rodrigues ${ }^{\S}$ \\ ${ }^{\ddagger}$ CEF.UP and Faculdade de Economia, Universidade do Porto. \\ ${ }^{\S}$ NIPE and School of Economics and Management, University of Minho.
}

September 2018

\begin{abstract}
This paper develops a dynamic model for the timing and terms of mergers. In contrast to other models, we show that firms agree about the timing independently from how the merger surplus is shared or their bargaining power. We show that, under asymmetry of information, the combination of surprises on the merger timing and the merger terms, can produce negative or positive abnormal announcement returns for the merging firms. The abnormal returns are also possible under perfect information, even if the announcements are expected by the market, and occur as a result of the event-study methodology.
\end{abstract}

Keywords: Merger terms, Merger timing, Bargaining, Uncertainty, Real Options, Event studies.

JEL codes: G34, D81.

\footnotetext{
*This research has been financed by the European Regional Development Fund through COMPETE 2020 - Programa Operacional Competitividade e Internacionalização (POCI) and by Portuguese public funds through FCT (Fundação para a Ciência e Tecnologia, I.P.) in the framework of the projects POCI01-0145-FEDER-006683 (Artur Rodrigues) and POCI-01-0145-FEDER-006890 (Paulo J. Pereira). We thank Alcino Azevedo, Bart Lambrecht, Dean Paxson, Elmar Lukas, Luís Aguiar-Conraria, Rosa BrancaEsteves, and participants of the 2015 Annual Real Options Conference for their helpful comments. Any remaining errors are the sole responsibility of the authors.

${ }^{\dagger}$ Corresponding author. Faculdade de Economia, Universdidade do Porto. Rua Dr. Roberto Frias, 4200-464 Porto (Portugal). E-mail: pjpereira@fep.up.pt; Phone: +351 225571100.
} 


\section{Bargaining merger terms and the effect on the announcement returns}

\section{Introduction}

The motivations that govern merger and acquisitions (M\&A) decisions are well established in the literature. Typically, when merging, firms look for gains related to operating efficiencies (e.g.: economies of scale), increased market power, economies by vertical integration, technology transfers, among others. ${ }^{\text {m }}$ These gains are generally presented in the form of synergies.

However, since the final outcome of a merger process is usually uncertain, companies may have an incentive to delay the decision, waiting for a given optimal timing. Recent literature addresses this topic, following the real options theory. For instance, Lambrecht (2004) studies the timing of mergers motivated by economies of scale, and Thijssen (2008) addresses the timing when both efficiency gains and diversification benefits are considered. The optimal timing (or strategic timing) appears also in Alvarez and Stenbacka (2006), Lambrecht and Myers (2007), Hackbarth and Morelled (2008), and in Bernile et al (2012).

Another important issue regarding M\&A is how the merger potential gains are split among the intervening firms. The split of potential gains is defined by the exchange terms of the merger, which is proposed by the acquiring firm and negotiated by both firms. Some literature discusses what drives the definition of the terms, how they can be determined and the effects on the value of merging firms. For instance, Lambrecht (20104) defines a two-round process where firstly the firms agree about the timing of the merger, maximizing the overall merger gains, and then the merger terms are defined as those that induce both firms to merge at this efficient threshold. A similar approach appears in Morellec and Zhdanov (2005) and Hackbarth and Morelled (2008). The terms of the merger play an important role in these papers, since they are the unique solutions that ensure that the firms agree on the efficient timing. Accordingly, the timing of the merger and the exchange terms seem to be closely related.

However, differently from the related literature, our paper suggests that the timing and the terms are not necessarily linked. In fact, our approach shows that the firms agree

\footnotetext{
${ }^{1}$ Zhu et aL (2017) study a particular case where mergers may occur even in the absence of economies of scale, namely, in the context of banking industry, when the merger is driven by the incentive of gaining the too-big-to-fail status.
} 
about the timing independently from how merger synergies are split, namely as a result of their bargaining power. The merger terms and the bargaining power are not needed to align firms behavior with the efficient threshold, suggesting that some other factors may explain how the surplus is shared. This result is obtained by relaxing the assumption that the merged firm is split between the intervening firms in fixed shares, independently from the relative value of firms before merging, which we argue is more realistic.

Related to our work is Banerjee et al. (2014), where firms negotiate the timing and then bargain the sharing rule. In their approach, as in Thijssen (2008), the bargaining power is assumed constant and exogenously given. Relaxing this assumption, we suggest that the bargaining power should depend on the value of the firms. As we will see, the sharing rule, instead of being an indirect measure of the bargaining power, turns to assume a direct correspondence with it. In such a context, Banerjee et al. (2014) becomes a special case of our model. Morellec and Zhdanov (2005) and Lambrecht (2004) are also special cases where bargaining power is determined by the firm's relative exercise costs.

The independence of timing and terms has important implications on how the market reacts to a merger announcement. In fact, the market formulates expectations on both the amount of synergies, that determines the timing, and the merger terms, which may depend, namely, on the relative negotiating power (bargaining power) of each firm, that can be influenced by takeover defenses, termination fees, and stock ownership, among others.

We show that some of the mixed results regarding the announcement returns of merger and acquisitions can be explained in the context of our model under asymmetry of information. In efficient markets, abnormal returns can only be explained by new information conveyed by the announcement. The announcement reveals information to the market about the merger gains or synergies and the merger terms, i.e how synergies will be split between the firms (Barraclough et al. 2013). Under asymmetry of information, the market can only form expectations about these parameter values, adjusting share prices depending on the (lack of) occurrence of a merger announcement. This process of incorporating information into share prices, can explain all sorts of abnormal returns, as computed using the event studies methodology. Incomplete information has also been considered before, in a dynamic mergers model by Morellec and Zhdanov (2005), who suggest that it plays a role in explaining positive announcement returns and a return run-up prior to the announcement. However, they can only explain negative abnormal returns for target firms introducing multiple competing bidders in the model. In our model, imperfect information is the only ingredient needed to produce negative and positive abnormal returns, 
for both firms.

We consider two settings for the asymmetry of information. In the first setting, asymmetry of information between the managers of both firms and the market can produce positive or negative abnormal returns for both the bidder and the target. Following $\mathrm{Ak}-$ tas et al. (2010) we show how our model is capable of explaining why bidder-initiated mergers produce higher bid premiums. In the second setting, by considering asymmetric information between the informed bidder manager and optimistic investors, we argue that our model can explain the prediction of the timing theory of merger waves suggested by Shleifer and Vishny (2003) and Rhodes-Kropf et al. (2005). Under this theory, informed bidder managers, acting rationally, take advantage of the relative overvaluation of the firm to engage in mergers, using stock rather than cash as means of payment, and generate abnormal announcement returns in "hot" markets.

We also show that abnormal announcement returns can also occur under perfect information, even if the announcement is expected by the market. Return run-ups or run-downs prior to the merger are expected depending on the type of the merger payoff. In this case the event-study methodology suggests that an unexpected return is observed, but it is simply the result of the natural dynamics of the state-variables.

The paper proceeds as follows. Section $\nabla$ presents a dynamic model to obtain the merger timing. Section 3 discusses the determinants of mergers terms. Section $\square$ shows that asymmetric information can explain the empirical mixed results on the announcement abnormal returns and also shows that they can occur under perfect information. Section 5 concludes.

\section{The timing of mergers}

Let us assume that two firms, $i$ and $j$, have the irreversible option to merge into a single firm benefiting from synergies. The value of the stand-alone firms, the merged firm and synergies, depend all on a single source of uncertainty, $x$, that behaves according to a geometric Brownian motion:

$$
d x=\mu x d t+\sigma x d w
$$

where $\mu<r, \sigma$, and $d w$ are, respectively, the drift under the risk-neutral measure, the volatility, and the increment of a Wiener process. $r$ is the constant risk-free interest rate.

When firms merge, they combine their activities and a merger surplus, $\alpha(x)$, is produced. The stand-alone firms' value is $V_{i}(x)$ and $V_{j}(x)$. The value of the merged firm is 
$V_{M}(x)=V_{i}(x)+V_{j}(x)+\alpha(x)$, which is shared by both firms: fraction $\gamma_{i}$ to firm $i$ and $1-\gamma_{i}$ for the other firm. ${ }^{\square}$

Therefore, the payoff of merging for firm $i$ is:

$$
\Pi_{i}(x)=\gamma_{i} V_{M}(x)-V_{i}(x)-K_{i}
$$

and for firm $j$ :

$$
\Pi_{i}(x)=\left(1-\gamma_{i}\right) V_{M}(x)-V_{j}(x)-K_{j}
$$

where $K_{i}$ and $K_{j}$ are sunk costs incurred by each firm.

If firms define the timing of the merger and then bargain how to split the surplus, the bargaining problem is:

$$
\max _{\gamma_{i}}\left[\gamma_{i} V_{M}(x)-V_{i}(x)-K_{i}\right]^{\eta_{i}(x)}\left[\left(1-\gamma_{i}\right) V_{M}(x)-V_{j}(x)-K_{j}\right]^{1-\eta_{i}(x)}
$$

where $\eta(x)$ is the bargaining power as a function of the state variable. Notice that, in contrast to Banerjee et al. (2014), the bargaining power in now non-constant, varying with $x$.

The solution for the value maximization problem is:

$$
\gamma_{i}(x)=\frac{V_{i}(x)+K_{i}+\eta_{i}(x)\left(\alpha(x)-K_{i}-K_{j}\right)}{V_{M}(x)}
$$

Plugging the solution for $\gamma_{i}(x)$ into Equation (च) and simplifying, we get the merger payoffs:

$$
\begin{aligned}
\Pi_{i}(x) & =\eta_{i}(x) \pi(x) \\
\Pi_{j}(x) & =\left(1-\eta_{i}(x)\right) \pi(x)
\end{aligned}
$$

where $\pi(x)=\alpha(x)-K$ is the net surplus of the merger, and $K=K_{i}+K_{j}$ is the aggregate sunk cost. Notice that the outcome of the bargaining game is essentially a discussion on how to share the merger surplus. The bargaining power will determine the stake each firm gets from the surplus produced by the merger. In other words, the merger terms $\left(\gamma_{i}(x)\right)$ can be mapped from the bargaining power $\left(\eta_{i}(x)\right)$.

Previous models have assumed that the merged firm is split between the two firms in

\footnotetext{
${ }^{2}$ As in Banerjee et al. (2014), a cash transfer can be also included, but the main results hold.
} 
fixed shares, independently from the relative value of firms before merging. For instance, in the Morellec and Zhdanov (2005) model, the state variable is precisely the stochastic relative value of the firms. This assumption allowed them to endogenously obtain the merger terms. These models assume that when a firm is considering to merge for a certain level $x$, and compares the payoff with the so-called continuation value, it assumes that merging later cannot change the merger terms or the bargaining power. On the contrary, in our setting the bargaining game produces merger terms that are not constant.

After bargaining for the terms, firms decide on the optimal timing to exercise the option to merge. Following standard procedures (Dixit and Pindyck 1994) any perpetual option on $x, O_{i}(x)$, must satisfy the following ordinary differential equation:

$$
\frac{1}{2} \sigma^{2} x^{2} O^{\prime \prime}(x)+\mu x O^{\prime}(x)-r O(x)=0
$$

yielding the following general solution ${ }^{\text {[S }}$ :

$$
O_{i}(x)=A^{+} x^{\nu^{+}}+A^{-} x^{\nu^{-}}
$$

where $\nu^{+}$and $\nu^{-}$are the solutions to the fundamental quadratic equation:

$$
\frac{1}{2} \sigma^{2} \nu(\nu-1)+\mu \nu-r=0
$$

The merger payoff $\pi(x)$ can accommodate a wide variety of merger surpluses for which it is possible to obtain an optimal merger timing with appropriate value-matching and smooth-pasting conditions for $O(x)$. Let us assume, for now, that $\pi(x)$ is strictly increasing/decreasing in $\mathbb{R}_{+}$and has a zero. For instance when a merger produces economies of scale and requires a sunk cost, a simple possible payoff would be $\pi(x)=\alpha x-K$. In this case the merger option would be equivalent to a call option. If a merger allows the merged firm to divest some assets in exchange for a fixed salvage value, the payoff can be modeled as $\pi(x)=K-\alpha x$, meaning that the merger option is similar to a put option.

When analyzing the option to merge, each firm must consider the optimal behavior of the other firm, i.e. what are the terms that the other firm requires in order to agree merging for different values of $x$. Firm $i$ considers the fraction of the merger surplus $(\pi(x))$ that the other firm, $j$, is willing to concede $\left(\eta_{i}(x)\right)$, such that every $x$ is an optimal

\footnotetext{
${ }^{3}$ Please notice that both $A^{+}$and $A^{-}$are positive, with + and - denoting the association with the respective sign of $\nu$.
} 
merger trigger. ${ }^{\text {. }}$ The value of the option to merge for firm $j\left(O_{j}(x)\right)$, with a bargaining power of $1-\eta_{i}(x)$, must satisfy the following boundary conditions:

$$
\begin{aligned}
& O_{j}(x)=A_{j}^{ \pm} x^{\nu^{ \pm}}=\left(1-\eta_{i}(x)\right) \pi(x) \\
& \nu^{ \pm} A_{j}^{ \pm} x^{\nu^{ \pm}-1}=\left(1-\eta_{i}(x)\right) \pi^{\prime}(x)-\eta_{i}^{\prime}(x) \pi(x)
\end{aligned}
$$

where $\eta_{i}(x)$ is firm $i$ share of the merger surplus that firm $j$ is willing to concede. Please notice that we require every $x$ to be an optimal trigger, and so these boundary conditions must be valid to every $x$, an not only for a single trigger $\left(x^{*}\right)$ as in standard models. Given that the payoff is determined by $\eta_{i}(x)$, this function can be defined in order to allow every $x$ to become a trigger for investment.

These boundary conditions can be reduced to the following differential equation, which $\eta_{i}(x)$ must solve:

$$
x \pi(x) \eta_{i}^{\prime}(x)+x \pi^{\prime}(x) \eta_{i}(x)-\nu^{ \pm} \pi(x) \eta_{i}(x)-x \pi^{\prime}(x)+\nu^{ \pm} \pi(x)=0
$$

Proposition 1. The value of the option to merge for firm $j$, that makes it indifferent to merge for any $x$ is:

$$
O_{j}(x)=C_{j} x^{\nu^{ \pm}}
$$

where $C_{j}>0$ is an exogenous parameter that influences the bargaining power, and the share of the merger surplus that firm $j$ is willing to concede to firm to $i$ is.

$$
\eta_{i}(x)=1-\frac{C_{j} x^{\nu^{ \pm}}}{\pi(x)}
$$

and

$$
\nu^{ \pm}=\frac{1}{2}-\frac{\mu}{\sigma^{2}} \pm \sqrt{\left(-\frac{1}{2}+\frac{\mu}{\sigma^{2}}\right)^{2}+\frac{2 r}{\sigma^{2}}}
$$

Firm $i$ must now consider $\eta_{i}(x)$ in its decision to merge. Taking into consideration

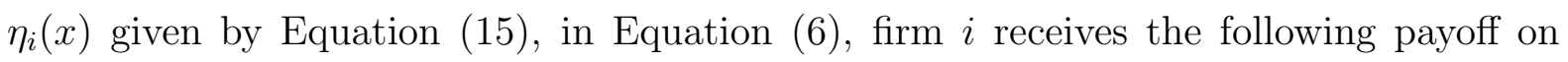

\footnotetext{
${ }^{4}$ Note that, as shown before, the merger terms are the result of the bargaining power $\eta_{i}(x)$, or, equivalently, the sharing rule of the merger surplus.

${ }^{5}$ As $0 \leqslant \eta_{i}(x) \leqslant 1, C_{j}$ must be in the following interval: $0 \leqslant C_{j} \leqslant \frac{\pi(x)}{x^{\nu}}$.
} 
merging at $x=x_{i}$ :

$$
\Pi_{i j}\left(x_{i}\right)=\pi\left(x_{i}\right)-C_{j} x_{i}^{\nu^{ \pm}}
$$

where $i j$ denotes the case when firm $i$ incorporates firm $j$ required terms.

Proposition 2. The value of the option to merge for firm $i$, taking into account the merger terms required by firm $j$, is:

$$
O_{i j}(x)= \begin{cases}\Pi_{i j}\left(x_{i}^{*}\right)\left(\frac{x}{x_{i}^{*}}\right)^{\nu^{+}} & \text {for } x<x_{i}^{*} \\ \Pi_{i j}(x) & \text { for } x_{i}^{*} \leqslant x<x_{i}^{* *} \\ \Pi_{i j}\left(x_{i}^{* *}\right)\left(\frac{x}{x_{i}^{* *}}\right)^{\nu^{-}} & \text {for } x \geqslant x_{i}^{* *}\end{cases}
$$

where

$$
\Pi_{i j}\left(x_{i}\right)=\pi\left(x_{i}\right)-C_{j} x_{i}{ }^{\nu^{ \pm}}
$$

and

a. For strictly increasing merger payoffs,

$x_{i}^{*}$ is the solution to the following equation:

$$
\nu^{+} \pi\left(x_{i}^{*}\right)-\pi^{\prime}\left(x_{i}^{*}\right) x_{i}^{*}=0,
$$

$x_{i}^{* *}$ is the solution to the following nonlinear equation:

$$
\nu^{-} \pi\left(x_{i}^{* *}\right)-\pi^{\prime}\left(x_{i}^{* *}\right) x_{i}^{* *}-\nu^{-} C_{j} x_{i}^{* * \nu^{+}}=0 .
$$

b. For strictly decreasing merger payoffs, $x_{i}^{*}$ is the solution to the following nonlinear equation:

$$
\nu^{+} \pi\left(x_{i}^{*}\right)-\pi^{\prime}\left(x_{i}^{*}\right) x_{i}^{*}-\nu^{+} C_{j} x_{i}^{* \nu^{-}}=0
$$

$x_{i}^{* *}$ is the solution to the following equation:

$$
\nu^{-} \pi\left(x_{i}^{* *}\right)-\pi^{\prime}\left(x_{i}^{* *}\right) x_{i}^{* *}=0 .
$$

Firm $i$ will be willing to merge when $x$ crosses $x_{i}^{*}$ from below. If, for any circumstance, 
the first observation of $x$ occurs at a higher level, merging will only be optimal for $x<x_{i}^{* *}$. This second trigger is relevant if the starting value of $x$ is above $x_{i}^{* *}$, and merging becomes optimal when $x$ crosses $x_{i}^{* *}$ from above.

For strictly increasing merger payoffs, the only meaningful trigger is $x_{i}^{*}$ (Equation $(\mathbb{2 0})$ ), as it can be shown that at the other trigger $\left(x_{i}^{* *}\right)$, mergers are not possible, because the two firms will not agree on the merger terms. For strictly decreasing payoffs the relevant trigger is $x_{i}^{* *}$ (Equation ([2:3)).

The most relevant characteristic of the solution is that the timing of mergers (Equations ([201) and ([2:3)) is independent of the bargaining power $\left(\eta_{i}(x)\right)$ or, equivalently, the merger terms $\left(\gamma_{i}(x)\right)$. Both firms agree to merge in the same timing, but the terms of the merger are not determined endogenously by the parameters that explain the trigger for merging.

Another relevant characteristic is that, depending on the type of merger payoff, mergers can be pro-cyclical, in the case of mergers induced by economies of scale or market power gains, and can occur in recessions, when motivated by divestment options, for instance. More generally, a merger surplus can even be an "U-shaped" concave or an inverted "U-shaped" convex function, for which there are two trigger values of $x$ that induce mergers. For concave payoffs, mergers occur for intermediate values of the state variable, and for convex payoffs, mergers occur for the outer values of the state variable, and firms wait for the intermediate values.

The individual firms' maximizing behavior is now compared to a central planner's decision.

Proposition 3. The trigger for merging of the individual firms is the same as that of a central planner maximizing the overall payoff $\Pi_{C}(x)=\pi(x)$.

Proposition B shows that the solutions of previous models (e.g.: Lambrecht (2004), Morellec and Zhdanov (2005)) are obtained in our setting, since they show that the individual firms' timing is also the central planner's timing. However, in their models the merger terms are endogenous and unique. In other words they need to find the terms that align the individual behavior with that of the central planner, whereas, in our case, the alignment is a natural result of the individual firms' optimal decisions. 


\section{The merger terms}

In the related literature the terms of the merger are usually endogenously determined, i.e. the terms result as part of the global solution.

Lambrecht (2004) defines a two round procedure where parties first negotiate and agree about the timing, and then decide how to share the new company. In the first round the author assumes that it is in the best interest of each firm to merge at the central planner trigger. In the second round they agree on the terms that induce both to exercise the merger option at that optimal timing. In doing so, he assumes that those terms are constant over time and are independent of the state variables. In this model, the post-merging shareholding is unique and is a function of the stock of capital of each firm and the merger costs. Our model differs from this model in two important aspects. First, we do not need to impose the restriction that the firms must ex ante agree to merge on the central planner trigger. The central planner solution arises as the result of the equilibrium strategies of each firm. Second, we show that there are multiple acceptable sharing rules.

The approach of Morellec and Zhdanov (2005) is different. First, firms compute their own optimal merger timing, and then the sharing rule is found as the unique solution that ensures both firms agree on the timing. They conclude that the timing is the same as the central planner solution. Although their model is different from Lambrecht (20104), if their procedure is used for the same model setting, it is straightforward to show that the solution is exactly the same. Differently from our model, the merger terms are unrealistically assumed to be constant and independent of the state variable, which produces an unique sharing rule, in contrast to the multiple viable sharing rules in our model.

Thijssen (2018) assumes that the share of the merged firm is a function of the state variables. However, in his model the timing and terms are obtained endogenously, being a function of each other. In our model they are independent. His model produces a single sharing rule, while in our model multiple solutions may exist. Using a Nash bargaining single stage game, he shows that the option value completely disappears and the timing is independent of the bargaining power. This results from the assumption that disagreement point of the game is such that the firm becomes a target and obtains a null merge payoff. Alvarez and Stenbacka (2006) also assume that the merger terms are determined through Nash bargaining. The exogenous constant bargaining power determines the merger terms.

The observation of the merger terms is however extremely difficult, if not impossible. 
In perfect markets, the shares in the merged firm are exactly the relative values of the firms before merging. The value of each firm before merging already includes the merger option value, i.e. a given expectation about the sharing rule of the merger surplus. The occurrence of any abnormal return can be explained as the result of a surprise to the market, either in terms of timing or the sharing rule of the merger surplus. However even under perfect information the return dynamics resulting from the option exercise can also explain the abnormal returns. We study these possible explanations in the following section.

\section{Explaining the announcement abnormal returns}

The majority of the literature on mergers and acquisitions traditionally reports empirical evidence showing positive returns for target firms and negative (or zero) returns for the shareholders of the acquirers (Jensen and Ruback (198:3), Jarrell and Poulsen (1989), Andrade et al. (2001), Eckbo (200)9), and Lin et al. (2010])). Value-loss for the acquiring shareholder is also reported by Moeller et al. (2005) for large deals in the late 90's.

Recent studies suggest mixed results. Martynova and Renneboog (2011) show evidence of positive abnormal returns for both parties, significant for the targets, but only slightly positive for the bidder (previously, similar results appear in Bradley et al. (1988)) . Barraclough et al. (2013) shows mixed signs for the returns, depending on the base price used in the analysis. However, the results indicate that the returns of the bidding firms are relatively small when compared with the returns of the target. In a different approach, opposite evidence is reported by Ahern (2012), where the average gains for target firms are only modestly larger than the gains obtained by the acquirers.

Different explanations for the realized abnormal returns have been suggested in the literature. Some of the arguments are: the relative size of the firms (e.g. Moeller et al. (2004)), the existence of information asymmetry (e.g. Moeller et al. (2007)), the success of the offer (e.g. Barraclough et al. (2013)), the rivalry of the merging firms (e.g. Song and Walkling $(2000)$ ), the form of payment (e.g. Gao (2011) and Barraclough et al. (2013)), and the nature (public or private) of the target firm (e.g. Fuller et al] (200(2)) among others.

In the context of the model herein presented, we follow the information asymmetry argument of Moeller et al. (2007). However, we show that, even for the case of perfect information, abnormal returns produced by merger announcements can be explained, albeit the announcement is expected by the market. Previously Hackbarth and Morelled (20)(18) 
have shown that the dynamics of the firm-level betas change in the period surrounding the announcement. In their model the betas change depending on the relative betas of the bidder and target firms and a run-up or run-down of betas are both possible. We also show that a return run-up or run-down is also possible in the case of a single factor model, simply depending on the type of the merger payoff.

Under information asymmetry, the abnormal returns are driven by the adjustment of prices to the information revealed by the announcement. In line with Barraclough et al. (2013), the announcement informs the market about both the merger gains (synergies) and the merger terms (how the synergies will be split between the firms shareholders). The market can only form expectations about this relevant piece of information, adjusting immediately the share prices once it becomes public. We show that this adjustment can produce all types of abnormal returns, depending on shareholders' prior assessment about the merger gains and the bargaining power of the managers.

\subsection{Abnormal returns under perfect information}

Under perfect information, the market anticipates the merger terms and timing. The merger announcement does not produce any price change. However, the exercise of the option to merge alters the return and risk dynamics.

The announcement effects are traditionally computed using the event study methodology, under which the return $(R)$ during the event window around the announcement date is measured against the expected return $(\hat{R})$, that is calculated using a given estimation window prior to the event. The abnormal return $(A R)$ is simply $R-\hat{R} .^{\text {(t) }}$ It is therefore important to know how the returns behave during those windows. ${ }^{\square}$

Before the merger, the value dynamics of firm $i, F_{i}(x)$, depends on the assets-in-place and the option to merge:

$$
d F_{i}(x)=d V_{i}(x)+d O_{i}(x)
$$

After the merger, the firm value dynamics is only a function of the assets-in-place:

$$
d F_{M}(x)=d V_{M}(x)
$$

\footnotetext{
${ }^{6}$ Please note that the absence of any abnormal return does not mean that there are no synergies. It simply means that the market is able to anticipate and incorporate in the prices both the synergies and the merger terms.

${ }^{7}$ The asset pricing implications of the exercise of real options have been studied before (Berk et al. 1099, 20104, Carlson et al 20104, 20106, 2010, Cooper 2006, Hackbarth and Morelled 20018, Zhang 20015).
} 
The returns depend on the functional form of both the assets in place and the option to merge. Let us assume that the assets-in-place value has the following functional form:

$$
V_{i}(x)=\phi_{i} x^{\theta}
$$

where $\phi_{i}>0$ and $\theta \geqslant 1$.

This general function encompasses the Lambrecht (20)4) model $(\theta>1)$, and Morelled and Zhdanov (2005) and Hackbarth and Morelled (2008) models $(\theta=1)$. Also for the sake of simplicity, let us assume that the merger surplus is strictly increasing or decreasing, which implies that the option to merge is a perpetual call or put, respectively:

$$
O_{i}(x)=A_{i}^{ \pm} x^{\nu^{ \pm}}
$$

Furthermore we assume that the assets-in-place are less risky than the call option to merge, i.e. $\theta<\nu^{+}$, which also occurs in Lambrecht (20104).

Proposition 4. The overall return of the firm value prior to the merger is:

$$
R_{t<\tau}=\mu_{V}+\frac{O_{i}(x)}{F_{i}(x)}\left(\mu_{O}-\mu_{V}\right)
$$

where

$$
\begin{aligned}
& \mu_{V}=\theta \mu+\frac{1}{2} \theta(\theta-1) \sigma^{2} \\
& \mu_{O}=r+\nu^{ \pm}(\mu-r)
\end{aligned}
$$

and after merging:

$$
R_{t>\tau}=\mu_{V}
$$

where $\tau$ denotes the first time the trigger for merging is hit.

The comparison of returns before $\left(R_{t<\tau}\right)$ and after $\left(R_{t>\tau}\right)$ the merger allows us to state the following:

Corollary 1. The average return before the merger is higher (lower) than the return after the merger for a merger surplus strictly increasing (decreasing) in the state variable $x$, which means that, under perfect information, the announcement of a merger in expansions (recessions) produces negative (positive) abnormal returns. 
The return before the merger is a weighted average of the assets-in-place and option returns. When the option to merge is a call option, the return of the option is higher than the assets-in-place return. We expect to observe a run-up in the returns, as we approach the trigger for the merger. When the merger occurs, the exercise of the call option reduces the return to the assets-in-place return. The event study methodology will suggest a negative abnormal return since the return in the event window is lower that the expected return $(R<\hat{R})$. On the contrary, when the option to merge is a put option, we will observe a run-down in the returns prior to the merger and a jump to the assets-in-place return when the trigger is reached, producing a positive abnormal return.

Corollary 2. As we approach the trigger for the merger it is expected to observe a return run-up (run-down) when the option to merge is a call (put) option.

A similar result appears in Hackbarth and Morelled (20)(18), but for the firm-level betas, that change depending on the relative betas of the bidder and target firms when the merger is a call option. We show that, in the case of a single factor model, a run-up or run-down in returns is also possible, according to the type of the merger payoff.

\subsection{Abnormal returns under asymmetric information}

Let us consider the asymmetry of information in two different contexts. Firstly, the asymmetric information between the merging firms and the market, where the managers of both firms have all the relevant information about the synergies, while the market is only able to form some expectation about the level of those synergies. As we will see, depending on market's over(under)estimation of the synergies, combined negative (positive) abnormal returns can be expected. Secondly, in line with Shleifer and Vishny (200:3) and Rhodes-Kropf et al. (20015), we assume a more severe asymmetric information setting, where only the bidder knows the true synergy, while the target shares the market's optimistic prospects about the merger synergies and bidder's value.

\subsubsection{Asymmetric information between the firms and the market}

Let us assume that the managers of merging firms have private information about the synergies. The market can only form expectations about the value of synergies, $(\hat{\pi}(x))$ that translate into an expected trigger for the merger $\left(\hat{x}^{*}\right)$, and an expected bargaining power $\left(\hat{\eta}_{i}\right)$, or the equivalent merger terms $\left(\hat{\gamma}_{i}\right)$, that do not affect the trigger as shown 
before. The announcement of the merger reveals both the synergies and the terms negotiated by the managers, and the market will react correcting its expectations based on this new piece of information. Let us consider the two possible cases where either the market overestimates or underestimates the synergies.

\section{Case 1: The market overestimates the synergies}

Assume that the market (continuously) overestimates the synergies, pushing the expected trigger of the merger to a level that it is below the true merger trigger $\left(\hat{x}^{*}<x^{*}\right)$. If $x$ hits $\hat{x}^{*}$ and the merger is not announced, the market incorporates the information and updates its expectation, decreasing the level of expected synergies, that however remain overestimated. This process of updating the expectations about the synergies continues as the state-variable $x$ increases in value (the market extracts information of the absence of a merger announcement) until the moment when the merger is finally announced at the optimal moment.

Notice that, due to this continuous update process, the merger will happen at the moment expected by the market, producing no surprise. In fact, the announcement only confirms what was the market expectations about the synergies at that particular moment, and so no price update occurs for synergies.

For the firms as a whole, and for the reasons presented in section 4.1 , a combined negative (positive) abnormal return is expected for call (put) type of mergers.

However, in addition to the true synergies, the announcement also reveals to the market the terms of the merger, i.e., how the merger surplus will be shared between the two firms. This sharing rule results from a negotiation between the managers of each firm and will depend on their (relative) bargaining power. Accordingly, the merger announcement also reveals the true $\gamma_{i}$, which can be different (or not) from the one expected by the market $\left(\hat{\gamma}_{i}\right)$.

It is easy to see that in case of $\gamma_{i}=\hat{\gamma}_{i}$, the abnormal return of each firm will be similar to the combined abnormal return (negative for mergers like calls and positive for merger like puts). However, in all other cases, particularly when one firms unexpectedly captures relatively more (less) synergies than the other, a positive (negative) surprise in $\gamma_{i}$ can produce a final positive (larger negative) abnormal return to the firm.

All possible signs for the abnormal returns appear in Table $\square$ : 


\begin{tabular}{|l|ccc|ccc|}
\hline & \multicolumn{3}{|c|}{ Call option } & \multicolumn{3}{c|}{ Put option } \\
\hline & Firm 1 & Firm 2 & Comb. & Firm 1 & Firm 2 & Comb. \\
\hline Smaller $\gamma_{1}$ & - & $+/-$ & - & $+/-$ & + & + \\
Expected $\gamma_{1}$ & - & - & - & + & + & + \\
Larger $\gamma_{1}$ & $+/-$ & - & - & + & $+/-$ & + \\
\hline
\end{tabular}

Table 1: Summary of the announcement returns in the case of an overestimation of synergies by the market. $\gamma_{1}$ stands for the share of the merged firm accruing to firm 1.

\section{Case 2: The market underestimates synergies}

Let us now analyze the case where the market underestimates the synergies. When this happens, since the trigger expected by the market is higher than the true merger trigger $\left(\hat{x}^{*}>x^{*}\right)$, the announcement always reveals to be a surprise for the market, due to the higher (than expected) merger synergies. Naturally, stocks prices will react positively to this new information. For sufficiently high revealed synergies, the combined abnormal return can become positive, compensating the natural effect of the event study methodology (section 4.0 ).

Combining the effects of the merger terms revealed at the announcement, Table $\nabla$ presents all possible signs for the abnormal returns in the case of a market underestimation of the synergies:

\begin{tabular}{|l|ccc|ccc|}
\hline & \multicolumn{3}{|c|}{ Call option } & \multicolumn{3}{c|}{ Put option } \\
\hline & Firm 1 & Firm 2 & Comb. & Firm 1 & Firm 2 & Comb. \\
\hline Smaller $\gamma_{1}$ & $+/-$ & $+/-$ & $+/-$ & $+/-$ & + & + \\
Expected $\gamma_{1}$ & $+/-$ & $+/-$ & $+/-$ & + & + & + \\
Larger $\gamma_{1}$ & $+/-$ & $+/-$ & $+/-$ & + & $+/-$ & + \\
\hline
\end{tabular}

Table 2: Summary of the announcement returns in the case of an underestimation of synergies by the market. $\gamma_{1}$ stands for the share of the merged firm accruing to firm 1.

\section{Further analysis of the two cases}

When the option to merge is a call option, the announcement produces returns that can be positive or negative, depending on the combination of the effects of the difference 
in returns prior e post merger (negative effect) and the surprise in the announcement (positive effect). When the asymmetry of information on the synergies is small, the surprise effect may not be sufficient to overcome the return effect, making more likely the negative announcement returns. These negative effects can be offset by the positive effect of a larger than expected share of the synergies captured by one of the firms. The combined value-weighted return present mixed results.

When the option to merge is a put option, the announcement produces positive abnormal returns for both firms (from both the returns and surprise effects). A lower than expected share of the synergies reduces the abnormal return, and it can become negative for the firm that captures a smaller than expected share. For this case, the combined return is always positive.

Notice that since in our model the roles of bidder and target are not endogenously determined, we can explain positive, null and negative abnormal returns for both firms.

Morellec and Zhdanov (2005) have also proposed a real options model where incomplete information of the market regarding the parameters of the merger plays a role in explaining positive announcement returns and a return run-up prior to the announcement. However, they can only explain negative abnormal returns for target firms introducing multiple competing bidders in the model. In our model, imperfect information is the only ingredient necessary to produce negative and positive abnormal returns, for both firms. Furthermore, and contrary to their proposition, a negative combined effect is possible in the case of call options, if the surprise effect is not sufficient to overcome the return effect.

Our model can also explain the results suggested by recent literature, revealing that the deal initiation is important for the premiums paid by the bidders. ${ }^{\square}$ Masulis and Simsir (2015) show that bidders initiate $63 \%$ of the mergers, while targets initiate the remaining 37\%. According to Aktas et al. (2010) targets receive lower premiums when they initiate the deal compared with bidder-initiated ones.

As suggested by Aktas et al. (2010), when the target initiates the deal, it signals a willingness to sell, resulting in a weaker bargaining power. In our setting, this translates into a smaller than expected $\gamma$, which results in lower premiums for the target, as well as higher premiums for the bidder, as reported by Aktas et al. (2010) and Masulis and Simsir (2015). On the other hand, a bidder-initiated deal induces him to offer higher premiums to the target in order to prevent competition from other bidders (Fishman

\footnotetext{
${ }^{8}$ Our model deals with friendly mergers, where the role of each firm (i.e. being a bidder or target) is not explicitly addressed. Please refer to Chen and Wang (2015) for a dynamic model where the initiation roles are endogenous.
} 
1988), which in our setting means an unexpected higher $\gamma$ for the target, i.e. a higher premium.

\subsubsection{Asymmetric information between the bidder and all other participants}

Shleifer and Vishny (2003) and Rhodes-Kropf et al. (20105) propose a market timing theory for merger waves, arguing that investors' optimism, leading to the misvaluation of bidders and merger synergies, drives merger waves in "hot" market periods. The informed bidder managers, acting rationally, take advantage of the relative overvaluation of the firm to engage in mergers, using stock rather than cash as means of payment. This theory assumes that the bidder managers know the true value of the firm and the merger synergies, but all other participants (including the target) overestimate them, and stick to their beliefs in the short run, even when the announcement occurs. Ang and Cheng (2006) show that during the hot periods, overvalued firms prefer equity to cash as means of payment in mergers. Rosen (2006) also finds evidence that mergers announced in "hot" markets outperform in the short-run those announced in "cold" markets. The explanation offered is consistent with the investor sentiment playing an important role, with optimistic investors reacting favorably to merger announcements.

In our setting, the market overpricing of the bidder value, allows him to claim a higher share in the merged firm (Equation (15)). It can also be argued that, because the target aligns with the market the overoptimism about the bidder value, it concedes a higher bargaining power to the bidder, therefore capturing a smaller share of the merger surplus. The bidder managers, who have the true knowledge about the firm and synergies valuation, fearing a market correction, have an incentive to anticipate a merger announcement. As suggested by Shleifer and Vishny (2003) they can even enter into non-synergistic mergers, just to take advantage of the misvaluation of firms. Delaying the decision to merge can be costly to the bidder, as it can lose the advantage of the overvaluation. While the suboptimal merger timing reduces the true overall merger surplus, the theory assumes that the market does not recognize that in the short run. An abnormal positive return, similar to that of case 2 of the previous section, is produced when the manager announces a merger sooner than expected by the market, because the bidder managers fear that the overvaluation may be corrected before it market's trigger is reached. 


\section{Conclusions}

This paper develops a dynamic real options model for the timing and terms of mergers, extending and generalizing previous models, both under perfect and asymmetric information. The main results and empirical insights are summarized below.

First, under perfect information, we show that firms always agree on the merger timing independently from how the surplus is shared between firms, and this timing is shown to be the same as that of a central planner. Contrary to most of the previous related models, the terms are shown not to be unique, and must depend on some exogenous factor, namely the bargaining power of each firm. The determinants of the mergers terms are therefore central for explaining how the market reacts to the announcement of the merger.

Second, under perfect information, abnormal returns, as measured using the eventstudy methodology, can be produced by merger announcements, even if they are expected by the market. We also show that return run-ups or run-downs are expected depending on the type of the merger payoff. In this case the event-study methodology suggests that an unexpected return is observed, while the natural dynamics of the state-variables is sufficient to explain the results.

Third, under asymmetry of information between managers and the market, the merger announcement also produce abnormal returns, resulting from surprises both in the merger timing and the merger terms. Negative or positive abnormal returns are possible for each firm, consistent with the empirical evidence.

Further research could also consider the effect of managers compensation along with takeover incentives and defenses.

\section{References}

\section{References}

Ahern, K. R.: 2012, Bargaining power and industry dependence in mergers, Journal of Financial Economics 103(3), 530-550.

Aktas, N., De Bodt, E. and Roll, R.: 2010, Negotiations under the threat of an auction, Journal of Financial Economics 98(2), 241-255. 
Alvarez, L. H. R. and Stenbacka, R.: 2006, Takeover Timing, Implementation Uncertainty, and Embedded Divestment Options, Review of Finance 10(3), 417-441.

Andrade, G., Mitchell, M. and Stafford, E.: 2001, New evidence and perspectives on mergers, Journal of Economic Perspectives 15(2), 103-120.

Ang, J. S. and Cheng, Y.: 2006, Direct evidence on the market-driven acquisition theory, Journal of Financial Research 29(2), 199-216.

Banerjee, S., Güçbilmez, U. and Pawlina, G.: 2014, Optimal exercise of jointly held real options: A nash bargaining approach with value diversion, European Journal of Operational Research 239(2), 565-578.

Barraclough, K., Robinson, D. T., Smith, T. and Whaley, R. E.: 2013, Using option prices to infer overpayments and synergies in M\&A transactions, Review of Financial Studies 26(3), 695-722.

Berk, J. B., Green, R. C. and Naik, V.: 1999, Optimal investment, growth options, and security returns, The Journal of Finance 54(5), 1553-1607.

Berk, J. B., Green, R. C. and Naik, V.: 2004, Valuation and return dynamics of new ventures, Review of Financial Studies 17(1), 1-35.

Bernile, G., Lyandres, E. and Zhdanov, A.: 2012, A theory of strategic mergers, Review of Finance 16(2), 517-575.

Bradley, M., Desai, A. and Kim, E. H.: 1988, Synergistic gains from corporate acquisitions and their division between the stockholders of target and acquiring firms, Journal of Financial Economics 21(1), 3-40.

Carlson, M., Fisher, A. and Giammarino, R.: 2004, Corporate investment and asset price dynamics: implications for the cross-section of returns, The Journal of Finance 59(6), 2577-2603.

Carlson, M., Fisher, A. and Giammarino, R.: 2006, Corporate investment and asset price dynamics: implications for seo event studies and long-run performance, The Journal of Finance 61(3), 1009-1034.

Carlson, M., Fisher, A. and Giammarino, R.: 2010, Seo risk dynamics, Review of Financial Studies 23(11), 4026-4077. 
Chen, Y. and Wang, Z.: 2015, Initiation of merger and acquisition negotiation with two-sided private information.

Cooper, I.: 2006, Asset pricing implications of nonconvex adjustment costs and irreversibility of investment, The Journal of Finance 61(1), 139-170.

Dixit, A. and Pindyck, R.: 1994, Investment Under Uncertainty, Princeton University Press, New Jersey.

Eckbo, B. E.: 2009, Bidding strategies and takeover premiums: A review, Journal of Corporate Finance 15(1), 149-178.

Fishman, M. J.: 1988, A theory of preemptive takeover bidding, The Rand Journal of Economics pp. 88-101.

Fuller, K., Netter, J. and Stegemoller, M.: 2002, What do returns to acquiring firms tell us? Evidence from firms that make many acquisitions, The Journal of Finance 57(4), 1763-1793.

Gao, N.: 2011, The adverse selection effect of corporate cash reserve: Evidence from acquisitions solely financed by stock, Journal of Corporate Finance 17(4), 789 - 808.

Hackbarth, D. and Morellec, E.: 2008, Stock returns in mergers and acquisitions, The Journal of Finance 63(3), 1213-1252.

Jarrell, G. A. and Poulsen, A. B.: 1989, The returns to acquiring firms in tender offers: Evidence from three decades, Financial Management 18(3), 12-19.

Jensen, M. C. and Ruback, R. S.: 1983, The market for corporate control: The scientific evidence, Journal of Financial Economics 11(1), 5-50.

Lambrecht, B.: 2004, The timing and terms of mergers motivated by economies of scale, Journal of Financial Economics 72(1), 41-62.

Lambrecht, B. and Myers, S.: 2007, A Theory of Takeovers and Disinvestment, The Journal of Finance 62(2), 809-845.

Lin, H.-C., Chou, T.-K. and Cheng, J.-C.: 2011, Does market misvaluation drive postacquisition underperformance in stock deals?, International Review of Economics 86 Finance 20(4), 690-706. 
Martynova, M. and Renneboog, L.: 2011, The performance of the european market for corporate control: Evidence from the fifth takeover wave, European Financial Management 17(2), 208-259.

Masulis, R. W. and Simsir, S. A.: 2015, Deal initiation in mergers and acquisitions.

Moeller, S. B., Schlingemann, F. P. and Stulz, R. M.: 2004, Firm size and the gains from acquisitions, Journal of Financial Economics 73(2), 201-228.

Moeller, S. B., Schlingemann, F. P. and Stulz, R. M.: 2005, Wealth destruction on a massive scale? A study of acquiring-firm returns in the recent merger wave, The Journal of Finance 60(2), 757-782.

Moeller, S. B., Schlingemann, F. P. and Stulz, R. M.: 2007, How do diversity of opinion and information asymmetry affect acquirer returns?, Review of Financial Studies 20(6), 2047-2078.

Morellec, E. and Zhdanov, A.: 2005, The dynamics of mergers and acquisitions, Journal of Financial Economics 77(3), 649-672.

Rhodes-Kropf, M., Robinson, D. T. and Viswanathan, S.: 2005, Valuation waves and merger activity: The empirical evidence, Journal of Financial Economics 77(3), 561603.

Rosen, R. J.: 2006, Merger momentum and investor sentiment: The stock market reaction to merger announcements, The Journal of Business 79(2), 987-1017.

Shleifer, A. and Vishny, R. W.: 2003, Stock market driven acquisitions, Journal of Financial Economics 70(3), 295-311.

Song, M. H. and Walkling, R. A.: 2000, Abnormal returns to rivals of acquisition targets: A test of theacquisition probability hypothesis', Journal of Financial Economics $\mathbf{5 5}(2), 143-171$.

Thijssen, J.: 2008, Optimal and strategic timing of mergers and acquisitions motivated by synergies and risk diversification, Journal of Economic Dynamics and Control 32(5), 1701-1720.

Zhang, L.: 2005, The value premium, The Journal of Finance 60(1), 67-103. 
Zhu, J., Li, G. and Li, J.: 2017, Merge to be too big to fail: A real option approach, International Review of Economics \& Finance 51, 342-353.

\section{Appendix}

Proof of Proposition 7 . Using a compact notation for the strictly increasing and decreasing payoffs, the value-matching and smooth-pasting conditions form firm $j$ are:

$$
\begin{aligned}
& A_{j}^{ \pm} x^{\nu^{ \pm}}=\left(1-\eta_{i}(x)\right) \pi(x) \\
& \nu^{ \pm} A_{j}^{ \pm} x^{\nu^{ \pm}-1}=\left(1-\eta_{i}(x)\right) \pi^{\prime}(x)-\eta_{i}^{\prime}(x) \pi(x)
\end{aligned}
$$

Reducing to a single equation, $\eta_{i}(x)$ is the solution to the following differential equation:

$$
x \pi(x) \eta_{i}^{\prime}(x)+x \pi^{\prime}(x) \eta_{i}(x)-\nu^{ \pm} \pi(x) \eta_{i}(x)-x \pi^{\prime}(x)+\nu^{ \pm} \pi(x)=0
$$

yielding:

$$
\eta_{i}(x)=1-\frac{C_{j} x^{\nu^{ \pm}}}{\pi(x)}
$$

where $C_{j}$ is an exogenous constant.

Replacing in Equation (प), the value of the option to merge for firm $j$ becomes:

$$
O_{j}(x)=C_{j} x^{\nu^{ \pm}}
$$

and, therefore, $C_{j}>0$.

Proof of Proposition 国. Given that $\nu^{+}>0, \nu^{-}<0, \eta_{i}(x)<1$, and $C_{j}>0, \lim _{x \rightarrow+\infty} \Pi_{i j}(x)=$ $-\infty$, and $\lim _{p \rightarrow 0} \Pi_{i j}(x)<0$. The option value $O_{i j}(x)$ must be non-negative, and therefore $\lim _{x \rightarrow+\infty} O_{i j}(x)=0$, and $\lim _{x \rightarrow 0} O_{i j}(x)=0$. Therefore, both constants $A_{i j}^{+}$and $A_{i j}^{-}$in the general solution ( $(\mathbb{Q})$ can not be set to 0 , and $O_{i j}(x)$ is a concave function, producing two possible merger triggers:

$$
O_{i j}(x)= \begin{cases}A_{i j}^{+} x^{\nu^{+}} & \text {for } x<x_{i}^{*} \\ \Pi_{i j}(x) & \text { for } x_{i}^{*} \leqslant x<x_{i}^{* *} \\ A_{i j}^{-} x^{\nu^{-}} & \text {for } x \geqslant x_{i}^{* *}\end{cases}
$$

a. For strictly increasing merger payoffs, the first trigger $x_{i}^{*}$ is obtained with the usual 
boundary conditions:

$$
\begin{aligned}
& A_{i j}^{+} x_{i}^{* \nu^{+}}=\pi(x)-C_{j} x_{i}^{* \nu^{+}} \\
& \nu^{+} A_{i j}^{+} x_{i}^{* \nu^{+}-1}=\pi^{\prime}(x)-\nu^{+} C_{j} x_{i}^{* \nu^{+}-1}
\end{aligned}
$$

Solving these two equations, we obtain $x_{i}^{*}$ :

$$
\nu^{+} \pi\left(x_{i}^{*}\right)-\pi^{\prime}\left(x_{i}^{*}\right) x_{i}^{*}=0
$$

The second trigger $x_{i}^{* *}$ is obtained with the following boundary conditions:

$$
\begin{aligned}
& A_{i j}^{-} x_{i}^{* \nu^{-}}=\pi(x)-C_{j} x_{i}^{* \nu^{+}} \\
& \nu^{-} A_{i j}^{-} x_{i}^{* \nu^{-}-1}=\pi^{\prime}(x)-\nu^{+} C_{j} x_{i}^{* \nu^{+}-1}
\end{aligned}
$$

$x_{i}^{* *}$ is the solution to the following nonlinear equation:

$$
\nu^{-} \pi\left(x_{i}^{* *}\right)-\pi^{\prime}\left(x_{i}^{* *}\right) x_{i}^{* *}-\nu^{-} C_{j} x_{i}^{* * \nu^{+}}=0 .
$$

b. For strictly decreasing merger payoffs, the first trigger $x_{i}^{*}$ is obtained with these boundary conditions:

$$
\begin{aligned}
& A_{i j}^{+} x_{i}^{* \nu^{+}}=\pi(x)-C_{j} x_{i}^{* \nu^{-}} \\
& \nu^{+} A_{i j}^{+} x_{i}^{* \nu^{+}-1}=\pi^{\prime}(x)-\nu^{+} C_{j} x_{i}^{* \nu^{-}-1}
\end{aligned}
$$

$x_{i}^{*}$ is the solution to the following nonlinear equation:

$$
\nu^{+} \pi\left(x_{i}^{*}\right)-\pi^{\prime}\left(x_{i}^{*}\right) x_{i}^{*}-\nu^{+} C_{j} x_{i}^{* \nu^{-}}=0 .
$$

The second trigger $x_{i}^{* *}$ is obtained with the following boundary conditions:

$$
\begin{aligned}
& A_{i j}^{-} x_{i}^{* \nu^{-}}=\pi(x)-C_{j} x_{i}^{* \nu^{-}} \\
& \nu^{-} A_{i j}^{-} x_{i}^{* \nu^{-}-1}=\pi^{\prime}(x)-\nu^{+} C_{j} x_{i}^{* \nu^{-}-1}
\end{aligned}
$$


Solving these two equations, we obtain $x_{i}^{* *}$ :

$$
\nu^{-} \pi\left(x_{i}^{* *}\right)-\pi^{\prime}\left(x_{i}^{* *}\right) x_{i}^{* *}=0
$$

Proof of Proposition 圆. For a central planner, the value-matching and smooth-pasting conditions are:

$$
\begin{aligned}
& A^{ \pm} x^{p^{\nu^{ \pm}}}=\pi\left(x^{p}\right) \\
& \nu^{ \pm} A^{ \pm} x^{p^{ \pm}-1}=\pi^{\prime}\left(x^{p}\right)
\end{aligned}
$$

Substituting $A^{ \pm} x^{\nu^{ \pm}}$in the second equation:

$$
\nu^{ \pm} \pi\left(x^{p}\right)-\pi^{\prime}\left(x^{p}\right) x^{p}=0
$$

For a merger payoff resembling a call option $\left(\nu^{+}\right), x^{p}=x^{*}$, and for the case of a put option $\left(\nu^{-}\right), x^{p}=x^{* *}$.

Proof of Proposition 因. The dynamics of the value of the assets-in-place, for a general function, $V_{i}(x)$, is given by Ito's lemma:

$$
d V_{i}(x)=\frac{\partial V_{i}(x)}{\partial x}[(\mu-\delta) x d t+\sigma x d w]+\frac{1}{2} \frac{\partial^{2} V_{i}(x)}{\partial x^{2}} \sigma^{2} x^{2} d t
$$

For a value of the functional form $V_{i}(x)=\phi_{i} x^{\theta}$, this reduces to:

$$
d V_{i}(x)=\left(\theta(\mu-\delta)+\frac{1}{2} \theta(\theta-1) \sigma^{2}\right) V_{i}(x) d t+\theta \sigma V_{i}(x) d w
$$

The diffusion process of the value of option to merge, prior to the expected merger timing, under the real measure, is given by: ${ }^{\text {! }}$

$$
d O_{i}(x)=\left(r+\nu^{ \pm}(\mu-r)\right) O_{i}(x) d t+\nu^{ \pm} \sigma O_{i}(x) d w
$$

\footnotetext{
${ }^{9}$ Please note, that using It's lemma:

$d O_{i}(x)=\frac{\partial O_{i}(x)}{\partial x} d x+\frac{1}{2} \frac{\partial^{2} O_{i}(x)}{\partial x^{2}}(d x)^{2}=\left((\mu-\delta) \nu^{ \pm} O_{i}(x)+\frac{1}{2} \sigma^{2} \nu^{ \pm}\left(\nu^{ \pm}-1\right) O_{i}(x)\right) d t+\sigma \nu^{ \pm} O_{i}(x) d w$.
}

From the fundamental quadratic Equation (四) we obtain Equation (5.5). 
The overall value dynamics prior to the merger is:

$$
\begin{aligned}
d F_{i}(x)= & \left(\left(\theta(\mu-\delta)+\frac{1}{2} \theta(\theta-1) \sigma^{2}\right) V_{i}(x)+\left(r+\nu^{ \pm}(\mu-r)\right) O_{i}(x)\right) d t \\
& +\left(\sigma V_{i}(x)+\nu^{ \pm} \sigma O_{i}(x)\right) d w
\end{aligned}
$$

and therefore the overall average return prior to the merger is:

$$
R_{t<\tau}=\frac{V_{i}(x)}{F_{i}(x)}\left(\theta(\mu-\delta)+\frac{1}{2} \theta(\theta-1) \sigma^{2}\right)+\frac{O_{i}(x)}{F_{i}(x)}\left(r+\nu^{ \pm}(\mu-r)\right)
$$

where $\tau$ denotes the first time the trigger for merging is hit.

Equation (57) simplifies to:

$$
R_{t<\tau}=\mu_{V}+\frac{O_{i}(x)}{F_{i}(x)}\left(\mu_{O}-\mu_{V}\right)
$$

where

$$
\begin{aligned}
& \mu_{V}=\theta(\mu-\delta)+\frac{1}{2} \theta(\theta-1) \sigma^{2} \\
& \mu_{O}=r+\nu^{ \pm}(\mu-r)
\end{aligned}
$$

Proof of Corollary $\mathbf{7}$. From Equations (50) and ([60):

$$
\mu_{O}-\mu_{V}=r+\nu^{ \pm}(\mu-r)-\theta(\mu-\delta)-\frac{1}{2} \theta(\theta-1) \sigma^{2}
$$

Additionally from the fundamental quadratic Equation (एण]) and since $\nu^{+}>\theta$

$$
\frac{1}{2} \sigma^{2} \theta(\theta-1)<r-\mu \theta
$$

Combining Equations (6]) and ([62):

$$
\mu_{O}-\mu_{V}>\left(\nu^{ \pm}-\theta\right)(\mu-r)
$$

which for a call option $\left(\nu^{+}\right)$is always positive, and for a put option $\left(\nu^{-}\right)$is always negative. 
Proof of Corollary 团. The value weight of the option to merge is:

$$
w_{i}(x)=\frac{O_{i}(x)}{F_{i}(x)}=\frac{O_{i}(x)}{V_{i}(x)+O_{i}(x)}=\frac{A_{i}^{ \pm} x^{\nu^{ \pm}}}{\phi x^{\theta}+A_{i} x^{\nu^{ \pm}}}
$$

Differentiating

$$
\frac{\partial w_{i}(x)}{\partial x}=\frac{A_{i}^{ \pm} \phi\left(\nu^{ \pm}-\theta\right) x^{\nu^{ \pm}+\theta-1}}{\left(\phi x^{\theta}+A_{i}^{ \pm} x^{\nu^{ \pm}}\right)^{2}}
$$

For a call option $\left(A^{+}>0\right.$ and $\left.\nu^{+}>1\right)$, and given $\nu^{+}>\theta$, as we approach the trigger from below, the weight of the option increases (the derivative is positive), producing an increase in the overall return. We expect, therefore, to observe a return run-up prior to the merger.

For a put option $\left(A^{-}>0\right.$ and $\left.\nu^{-}<0\right)$, as we approach the trigger from above (decreasing in $x$ ), the weight of the option also increases (the derivative is negative), but now produces a decrease in the overall return, given that the put option has lower return than the assets-in-place. We expect, therefore, to observe a return run-down prior to the merger. 